\title{
“GENTE DE FIBRA": A PRODUÇÃO DA ARTE EM PAPEL E MATERIAL RECICLÁVEL COMO FORMA DE DESENVOLVIMENTO SUSTENTÁVEL
}

\author{
FERREIRA, Edna Maria ${ }^{1}$ \\ LIMA, Tatiane Aparecida dos Santos ${ }^{2}$ \\ GRACIOLI, Maria Madalena ${ }^{3}$
}

Recebido em: 2009-05-22

Aprovado em: 2009-08-10

ISSUE DOI: $10.3738 / 1982.2278 .308$

Resumo: O desenvolvimento sustentável é uma alternativa capaz de assegurar às gerações futuras o direito de usufruir das mesmas oportunidades de desenvolvimento das gerações presentes. Neste contexto, esse texto analisa a "Cooperativa Mariense de Artesanato - Oficina Gente de Fibra", e procura demonstrar sua influência nos aspectos econômico, social e cultural no cotidiano dos cooperados, como experiência na comunidade e ainda, como garantia de subsistência e qualidade de vida. $\mathrm{O}$ foco de estudo foi o grupo de artesão da cidade de Maria da Fé - MG, que é organizado em cooperativa de artesanato que surgiu como proposta para geração de renda e educação ambiental, além de trabalhar a importância da reciclagem, atividades que são transmitidas à comunidade através da sensibilização, treinamento e comercialização dos produtos. Atualmente, essa cooperativa é referência no Brasil e no exterior; as peças produzidas são exportadas para vários países, valorizadas pelo trabalho artesanal e pela proteção do meio ambiente.

Palavras-chave: Desenvolvimento Sustentável, Cooperativa, Artesanato, Reciclável.

\section{“GENTE DE FIBRA" : PRODUCTION OF ART WITH PAPER AND WITH RECICLE MATERIAL AS MEANS OF SUSTAINABLE DEVELOPMENT}

SUMMARY: Sustainable development is an alternative able to assert to future generations the right of enjoy the same opportunities of development that present generations enjoy nowadays. In this context, the present study analyses the institution named "Cooperativa Mariense de Artesanato - Oficina Gente de Fibra" and, tries to demonstrate its influence in economic, social and, cultural aspects of co-opearators routine, as experience in the community and besides as subsistence guaranty and life quality. The study was made with a group of artisans from Maria da Fé city, Brazil; this group is organized in a cooperative that appeared as a proposal to produce income and ambient education, besides work with the importance of recycling. This activities are transmitted to community through sensibilization, training and, sell of products. Nowadays, this cooperative is a reference here in Brazil and in foreign lands. The pieces produced by the artisans are exported to several countries, the material is valorized by its artistic technique and by ambient protection.

Keywords: Sustainable Development. Cooperative. Artistic Technique. Recicle

\section{INTRODUÇÃO}

Sustentável é aquilo que se pode conservar; é o que pode permanecer, sem se esgotar, a partir dos processos de renovação. Hoje, não existe espaço suficiente no planeta para abrigar

\footnotetext{
${ }^{1}$ Assistente Social Graduada pela FASESP/UEMG/Passos-MG.

${ }^{2}$ Assistente Social Pós-Graduada pela FASESP/UEMG/Passos-MG.

${ }^{3}$ Doutora em Sociologia, professora da FASESP/UEMG/Passos-MG e professora e coordenadora do curso de Pedagogia da Faculdade de Filosofia Ciências e Letras de Ituverava.
} 
todo o resíduo das atividades humanas, sendo o resultado de produção e consumo desenfreados, em nome de tecnologia e bem estar do ser humano. Esbarramos no problema de esgotamento da biodiversidade, e degradação dos recursos naturais, em nome do crescimento populacional e expansão das fronteiras agrícolas, para sustento da população. Porém, é reconhecido por todos que é preciso garantir as necessidades do presente sem comprometer as necessidades das futuras gerações, ou seja, desenvolver em harmonia com as limitações ecológicas.

O presente artigo apresenta o desenvolvimento sustentável como uma alternativa capaz de assegurar às gerações futuras o direito de usufruir das mesmas oportunidades de desenvolvimento das gerações presentes. Neste contexto, a investigação analisa a "Cooperativa Mariense de Artesanato - Oficina Gente de Fibra", e procura demonstrar sua influência nos aspectos econômico, social e cultural no cotidiano dos cooperados, como experiência na comunidade e ainda, como garantia de subsistência e qualidade de vida. Nesse sentido, a cooperativa é um caminho para promover o desenvolvimento local e sustentável e, reduzir as desigualdades por meio da inclusão social. A investigação focou-se no grupo de artesão da cidade de Maria da Fé - MG, organizado em cooperativa de artesanato que surgiu como proposta para geração de renda e educação ambiental, além de trabalhar a importância da reciclagem, que são transmitidos à comunidade por meio da sensibilização, treinamento e comercialização dos produtos. Atualmente, essa cooperativa é referência no Brasil e no exterior, as peças produzidas são exportadas para vários países, valorizadas pelo trabalho artesanal e pela proteção do meio ambiente.

Dessa forma verifica-se que a utilização da Arte pode ser uma forma de sustentabilidade, pois ela representa a compreensão mais profunda e as mais puras inspirações de seu criador, ensina o ser humano a pensar, a compreender com mais clareza o trabalho realizado.

\section{SURGIMENTO E IMPORTÂNCIA DA ARTE EM PAPEL}

De acordo com estudos realizados, aproximadamente há mais de dois milhões de anos, o homem vive na terra, e a arte mais antiga de que se tem conhecimento foi criada há cerca de vinte e cinco mil anos, embora permaneça dúvida do exato momento em que surgiu. Gombrich enfatiza que:

[...] ignoramos como a arte começou, tanto quanto desconhecemos como teve início a linguagem, porém se aceitarmos que a arte significa o exercício de atividade tais como a edificação de templo e casas, a realização de pinturas e esculturas, ou tessitura de padrões, nenhum povo existe no mundo sem arte e nem tampouco é 
possível definir o momento como começou essa atividade humana. (GOMBRICH, 1995, p. 39).

A arte deve ser entendida como um produto da atividade visual mais humilde e mais comum do ser humano, baseada na sua vida diária e no seu cotidiano, não se pode considerála como uma atividade independente, misteriosamente inspirada do alto sem relação e sem possibilidades, mas sim relacioná-la com uma necessidade humana que envolve o ato de dar e de encontrar forma e significado, segundo a concepção do artista, como um instrumento de sua vida. Uma maneira refinada de entender quem somos e onde estamos. Janson expõe que:

A arte é considerada um diálogo visual, pois expressa a imaginação de seu criador tão claramente como se ele estivesse falando conosco, embora o objeto em si seja mudo. Até mesmo as declarações mais pessoais dos artistas podem ser compreendidas de alguma forma, ainda apenas a nível intuitivo. (JANSON, 1996, p.7).

Aranha e Martins atestam que:

[...] a arte aparece no mundo humano como forma de organização, como modo de transformar a experiência vivida em objeto de conhecimento, desta vez por meio do sentido, ela é um caso privilegiado de entendimento intuitivo do mundo, tanto para o artista que cria obras concretas e singulares quanto para o apreciador que se entrega a ela para penetrar-lhe o sentido. (ARANHA E MARTINS, 1993, p. 373).

E ainda sobre a arte como conhecimento, Faria e Garcia afirmam:

A arte é o último degrau do conhecimento e o artista o "mensageiro do invisível"'. Para Kolakowski a arte é um modo de perdoar a maldade e o caos do mundo". Segundo ela a "arte organiza as percepções do mau e do caótico, introduzindo a compreensão da vida de maneira tal que a presença do mal e do caos se convertem na possibilidade de iniciativa com respeito ao mundo, que leva em si mesmo seu próprio bem e seu próprio mal' '. (FARIA; GARCIA, 2003, p.42).

A sociedade não deseja a globalização que procura nos informar e nos transformar apenas em consumidores, mas a globalização que aproxima povos, proporcionando trocas de saberes e vivências fortalecedoras da mesma fraternidade.

A importância de incentivar o desenvolvimento de uma cidadania cultural, resgatando o imaginário artístico, a subjetividade para garantir o desenvolvimento humano e sua sustentabilidade, por meio da arte trará reencantamento e cultura da paz como caminho para convivência com a diversidade imposta pela alienação do processo produtivo globalizado.

$\mathrm{A}$ arte em papel ofereceu ao homem à possibilidade de expandir criatividade e substituir o metal, a seda, a madeira e muitos outros para que ficasse registrada na história a evolução da humanidade. 
Em 1950 quando o artista DART HUNTER, fez renascer a era do papel artesanal, que iniciou há 2000 anos com os Chineses. Muitos artistas já o tinham feito antes intuitivamente sem racionalização: Picasso, quando em 1911 cola em seu trabalho papeis texturizados, Breque, no ano seguinte, usa papel de parede imitando madeira. Essa inovação cubista teve desdobramento nas obras dadaísta KURT SHUITTER e também os três vertentes: $1^{\circ}$ papier collé cubista; $2^{\circ}$ ready-made de Duchamp; $3^{\circ}$ objet trouvé surrealista', (FIGUEIREDO, 1996, p.11).

O autor narra que:

A invenção do papel tal como a conhece tem sido atribuída a T'sai Lun, na China, no ano de 105 a.C. A forma chinesa de fabricar papel consistia em misturar casca de árvores, trapos e outros materiais fibrosos, e bate-lo até que formassem uma substância pastosa. Essa pasta era então colocada em uma grande tina e diluída em água. Em seguida, mergulhava-se um molde raso e poroso na solução pastosa. À medida que se retira o molde, a água escoava pelo fundo tipo peneira, deixando uma camada de fibras tornava-se uma folha de papel. (FIGUEIREDO, 1996, p.31).

A palavra papel é derivada do grego Papyrus, que significa junco.

\begin{abstract}
Fazer papel é, em certa medida, por a mão na massa. E é esse momento que se dá o fato interessante: quando mergulho no fazer e as mãos entram em contato com a matéria, fazendo um pequeno jogo para a direita e depois para a esquerda, com um indescritível movimento deixo o líquido escoar pelo nylon. Um momento mágico se inicia como a tacada do poema Zen "Quando um arqueiro Zen dispara a flecha, ele atinge a si próprio". (FIGUEIREDO, 1996, p.10).
\end{abstract}

Os diferentes tipos de trabalho sejam eles voltados para a escultura, colagem ou pintura, todos trazem em si a distinção de ser sempre papel artesanal fabricado com diferentes tipos de plantas (bouganville, espatódia, fibras de bananeira, fibras de sisal).

Saber fazer papel não depende apenas de um saber racional. Este saber não é suficiente para transformar a matéria-prima em papel. O enfoque principal é o devaneio. A questão vital é ter a consciência de que está contribuindo para uma causa maior; a manutenção do planeta e o prazer embutido na arte de fazer papel.

Crescer sem destruir tem sido o grande desafio deste século, reciclar é a palavra de ordem. A reciclagem de papel está obviamente atrelada à preservação da natureza e a perspectiva de, cada vez mais, evitar a derrubada de árvores. Reciclar e fazer papel significa a busca de novos caminhos sendo um desses caminhos o desenvolvimento sustentável e por que não, a satisfação e alegria de viver na construção e recriação do processo artesanal.

Dentro deste contexto de transformação da reciclagem do papel surgem as cooperativas entendidas como a união de pessoas que reúnem esforços, vontade e recursos com o objetivo de superar dificuldades, resolver problemas e gerar benefícios comuns que, isoladamente, se tornaria bem mais difíceis de conseguirem, essas ações ocorrem nos vários 
campos das atividades humanas, por meio da organização formal ou informal de grupos que visam o interesse comum, esta dinâmica supera limites e tem o poder de transformar e possibilitar a participação, relações e inclusão social de forma igualitária e competitiva.

O Grupo de artesão da cidade de Maria da Fé- MG, organizado como cooperativa de artesanato surge com proposta para geração de renda e de mão-de-obra qualificada, de educação ambiental, e de conceitos sobre a importância da reciclagem, que são transmitidos à comunidade, por meio da sensibilização, treinamento e comercialização dos produtos. O papel nada mais é, que um emaranhado de fibras vegetais, mas, ao transformar papel usado em novo, refaz-se essa trama e entrelaçando as fibras. Pela a transformação é possível confeccionar vários produtos entre muitas outras possibilidades. Dentro da proposta de desenvolvimento e inclusão social por meio da arte, observa-se um retorno positivo porque, ao mesmo tempo em que produz objetos, também preserva o meio ambiente e, gera renda aos trabalhadores envolvidos.

\section{DESENVOLVIMENTO SUSTENTÁVEL}

O objetivo do desenvolvimento sustentável, para uma sociedade particular, comunidade, município, estado, país, região, enfim para o planeta Terra, é melhorar o bemestar e a qualidade de vida individual e coletiva para as atuais e futuras gerações, fruto de uma integração harmônica entre os sistemas político, econômico, social e natural, reproduzindo a qualidade ambiental, o habitat humano, que permita o desenvolvimento integral biológico, social e psicológico do ser humano.

Não há desenvolvimento sustentável sem a participação da população. Todo mundo tem que fazer o dever de casa, preservar a identidade cultural dos povos e erradicar a pobreza, o preconceito e o massacre de populações, que são aspectos prioritários do desenvolvimento sustentável. Para alcançar o desenvolvimento sustentável, é preciso planejamento das ações humanas e reconhecimento de que os recursos naturais são finitos.

Mudar o modo de pensar e agir é o passo mais importante para garantir um mundo habitável para as gerações futuras. Qualquer medida visa agregar sustentabilidade ao desenvolvimento, necessariamente, passa pela educação, envolve mudança de mentalidade e conduta. Pois, acha-se que a ciência e a tecnologia sempre vão encontrar soluções para os problemas que se cria.

Sabe-se que o consumo atual não é sustentável, mas mesmo assim continua-se a estimular a insustentabilidade, é preciso uma efetiva mudança na atitude das pessoas. $\mathrm{O}$ desenvolvimento sustentável implica repensar todas as formas de produção e redefinição das 
relações entre homem e natureza, ainda não existe consenso sobre quem são os atores chaves desse novo modelo de desenvolvimento.

Refletir sobre desenvolvimento sustentável significa pensar em desenvolvimento econômico, social, político e cultural como sendo um direito de todos os seres humanos, onde se atende às necessidades presentes sem comprometer as necessidades futuras. Deve-se pensar em desenvolvimento no global, ou seja, na sustentabilidade econômica não só na fartura de investimentos, mas em administrar eficazmente os recursos produtivos, sendo necessário que os benefícios do crescimento econômico fiquem na região ou local para fortificar as fontes internas da poupança e investimento.

As condições básicas para que o desenvolvimento sustentável seja viável às pessoas e às organizações são as descobertas das necessidades individuais e coletivas. Portanto, deve-se entender quem é o ser humano e o se quer para construir um eixo central consciente, capaz de sustentar a organização de forma saudável e próspera, é necessário agregar a sustentabilidade, nas dimensões ecológica, social, cultural e política, tendo como referência o ser humano enquanto sujeito histórico, onde todos estejam comprometidos com a construção de um bem comum e a atividade econômica seja um meio de vida para todos os seres humanos e a natureza.

A Constituição Federal de 1988, no seu artigo 225, nos incisos I, VI, VII enfoca:

Todos têm direito ao meio ambiente ecologicamente equilibrado, bem de uso comum do povo e essencial à sadia qualidade de vida, impondo-se ao poder público e à coletividade o dever de defendê-lo e preservá-lo para as presentes e futuras gerações.Preservar e restaurar os processos ecológicos essenciais e promover o manejo ecológico das espécies e ecossistemas; promover a educação ambiental em todos os níveis de ensino e a conscientização pública para a preservação do meio ambiente; proteger a fauna e a flora, vedadas, na forma da lei, as práticas que coloquem em risco sua função ecológica, provoquem a extinção de espécies ou submetam os animais à crueldade.

E no Parágrafo $3^{\circ}$ determina que:

As condutas e atividades consideradas lesivas ao meio ambiente sujeitarão os infratores, pessoas físicas ou jurídicas, a sansões penais e administrativos, independentemente da obrigação de reparar os danos causados.

Deve-se entender o meio ambiente como um todo, não fragmentado, onde o espaço natural não está fora do espaço humano; ao contrário, um interage e depende do outro. Portanto, a percepção do meio ambiente passa por um entendimento mais profundo da relação homem-natureza e pela consciência que somos seres interligados, sendo a sua conservação um interesse de todos.

O desenvolvimento sustentável obedece ao duplo imperativo ético da solidariedade com as gerações presentes e futuras, e exige a explicitação de critérios de 
sustentabilidade social e ambiental e de viabilidade econômica. Estritamente falando, apenas as soluções que considerem estes três elementos, isto é, que promovam o crescimento econômico com impactos positivos em termos sociais e ambientais merece a denominação de desenvolvimento. (SACHS, 2004, p. 36).

O desenvolvimento sustentável é um processo com duas vertentes que devem ser compatibilizadas, e não deve ser separadas, onde uma depende da outra. Sendo em nível econômico e social, a primeira trata-se da continua produtividade de trabalho e da diversidade e complexidade as estruturas produtivas onde visa o aumento do bem estar social, a segunda promove a igualdade da sociedade, reduzindo as diferenças existentes nas camadas da população. (SACHS, 2004).

O desenvolvimento sustentável deve ser implementado mediante uma visão holística e sistêmica, inserida no complexo indissociável que une homem e natureza, concretizando entre ambos um convívio saudável e ecologicamente equilibrado, propiciando ao homem de hoje e ao de amanhã, uma sadia qualidade de vida, pois seu objetivo é equalizar, conciliar, encontrar um ponto de equilíbrio entre a atividade econômica e o uso adequado, racional e responsável dos recursos naturais, respeitando-os e preservando-os para as gerações atuais e subseqüentes.

Só assim pode-se alcançar o bem estar e a qualidade de vida individual, coletiva e o progresso em direção ao desenvolvimento sustentável sem democracia, livre comércio e respeito aos direitos humanos.

\section{COOPERATIVA “GENTE DE FIBRA": ARTE EM PAPEL E MATERIAL RECICLÁVEL}

A Cooperativa surgiu com as idéias do artista plástico Domingos Tótoras, que desejava realizar um trabalho inspirado na natureza, uma vez que, a cidade possui uma paisagem exuberante, assim seria possível desenvolver um artesanato diferente com identidade própria. Utilizava-se o papel machê com a fibra de bananeira, uma vez que havia grandes plantações de bananas na cidade e devido à monocultura ser a principal fonte de renda da população. Dessa forma, começou o trabalho, não tinham materiais necessários, mas a cooperativa desde o primeiro dia se auto-sustentou, pois todos colaboraram. Cada uma das mulheres levou liquidificador de casa para moer o papel. A igreja cedeu o espaço. Logo após o início do trabalho receberam o convite do Projeto "Mãos de Minas" para expor os trabalhos na Feira Nacional de Artesanato, na cidade de Belo Horizonte - MG. Tiveram apenas dois meses para produzir as peças, e todas foram vendidas. Com o tempo foi aparecendo vários parceiros como Mão de Minas, SEBRAE e Fundação Banco do Brasil.

Atualmente a cooperativa é utilizada como exemplo, uma vez que, não existe disputa pelo poder, cada um é um, e um são todos perante o grupo. Conquistaram o selo do Instituto 
de Qualidade Sustentável - IQS, de qualidade artesanal, tipo ISO 9.000, considerado economicamente viável, socialmente justo e ecologicamente correto. Pois, tudo que existe no universo tem uma ação e reação. É preciso sensibilizar o olhar, que é uma coisa de arte, já que estão em busca incessante, porque Maria da Fé era uma cidadezinha e hoje é reconhecida mundialmente, ou seja, moram na aldeia, mas são universais.

Com o surgimento da cooperativa, houve a transformação do trabalho individual para o coletivo "No complexo arranjo da convivência, se estabelece um código inquietante [...], de amizade com fins preciosos: ensinar, aprender, compreender, tolerar, seduzir, compartilhar, por conseqüência o companheirismo". (GRACIOLI, 2000, p.136-137). O companheirismo conduz a solidariedade, a um vinculo de união e interesses comuns, onde cada elemento do grupo de sente na obrigação de apoiar o colega.

Por meio do trabalho que desenvolvem são expressas habilidades que de forma criativa divulgam a identidade da cidade e a riqueza cultural de seus habitantes. Trabalha as técnicas da reciclagem e a transformação de material reaproveitável; desenvolvem reflexões e práticas de educação ambiental e reciclagem. Com gesto de civilidade incentiva a paz e o amor ao próximo, a noção de cidadania além de, minimizar os danos ambientais, inclusive para reduzir a cultura do desperdício, utilizando a prática dos três erres: reduzir, reutilizar e reciclar.

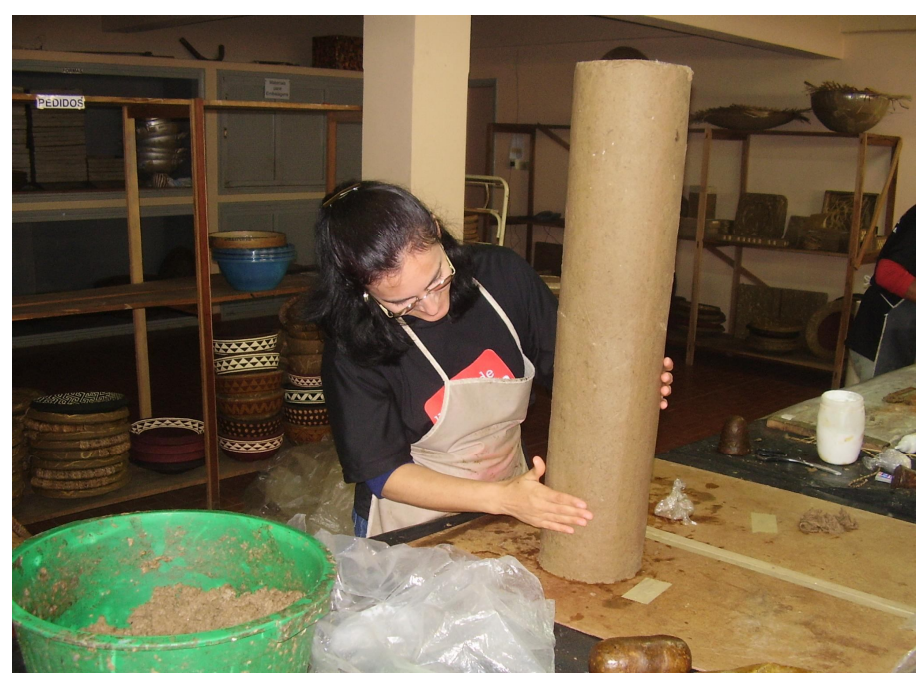

FIGURA 1: Cooperada trabalhando na moldagem das peças

A cooperativa também contribuiu para o crescimento de cada um de seus membros, tanto pessoal como financeiro, ou seja, hoje eles conseguem ter um novo olhar perante o mundo, pois, segundo os cooperados aqui ninguém sabe tudo, todos sabem algo e juntos sabem mais. O trabalho realizado eleva a auto-estima, a concentração, desenvolvendo as habilidades manuais e as potencialidades de cada indivíduo, já que, possibilita expressar em suas peças a verdadeira dimensão humana, e compartilhar um bem estar coletivo.

Nucleus, v.6, n.2, out. 2009 
Assim, esses artesãos, produtores desconhecidos e inventores de trilhas pelas quais caminham seus sonhos, conseguem organizar um ambiente onde circula a consciência do saber individual e a necessidade de compartilhar como o coletivo, que é o começo da fraternidade e da partilha, necessárias para a construção do desenvolvimento sustentável.

A Oficina "Gente de Fibra" conta com o apoio concentrado de todos seus membros, garantindo um trabalho eficaz e com isso conseguem alcançar resultados que beneficiam a comunidade, assim como um ambiente saudável, realiza a inclusão social, promove a geração de renda e conseqüentemente faz que seus membros possam exercitar a cidadania por meio da participação social, da interação e capacitação profissional, tendo como ponto de apoio o SEBRAE e o Projeto "Mãos de Minas".

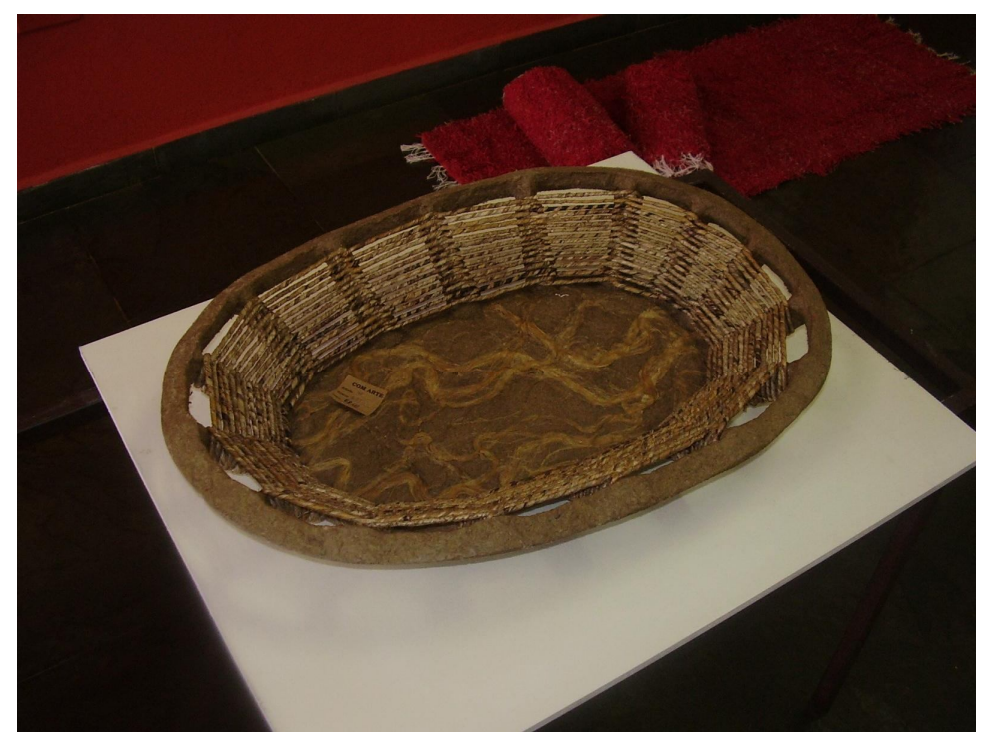

FIGURA 2: Fruteira (fibra de bananeira e papel)

A Cooperativa Mariense de Artesanato "Oficina Gente de Fibra" procura recuperar o horizonte da cidadania e com ele, a perspectiva da conquista da capacidade de fazer sua própria história, dessa forma tornou-se patrimônio de Maria da Fé, sendo um pólo de artesanato, de desing e, referência de desenvolvimento sustentável no Brasil.

\section{CONSIDERAÇÕES FINAIS}

Este trabalho teve como objetivo principal mostrar que por meio da Arte com produtos recicláveis se desenvolve a Sustentabilidade. É de fundamental importância à conscientização dos profissionais da área educacional e social para desenvolver ações de reciclagem, pois parte da garantia que qualidade de vida e os direitos básicos das populações dependem diretamente do meio ambiente em que elas estão inseridas. 
Reciclar constitui-se num novo padrão de desenvolvimento, que é o sustentável, que desponta gerando empregos e ajudando na preservação da natureza. Um novo quadro ecológico, econômico e social, ou seja, necessita ser criado e neste novo modelo, a capacitação, sensibilização e conscientização da população desempenham um papel fundamental. Solucionar a crise ecológico-social, com uma profunda raiz humana, exige empreender uma aprendizagem social para que a população adquira uma visão global, integrada, sensibilizada pelo meio ambiente.

Ressalta-se que a Arte em Papel e Material Reciclável favorece o desenvolvimento da sustentabilidade do município de Maria da Fé/MG. Os caminhos escolhidos para traçar o desenvolvimento sustentável nesse município foram satisfazer às necessidades básicas da comunidade e, ao mesmo tempo praticar a solidariedade com as futuras gerações criando um sistema social que garante emprego e segurança social.

O que distingue uma cooperativa das demais empresas comerciais são a educação e a participação dos seus membros, com objetivo de proporcionar aos cooperados e suas famílias uma ampla experiência de diálogo, ação e reflexão. A perspectiva a ser alcançada é que venham desenvolver a visão crítica da realidade, e que através da ação grupal (coletiva) seja possível transformar a sociedade.

O estudo aponta que a Cooperativa Mariense de Artesanato, Oficina "Gente de Fibra" da cidade de Maria da Fé - MG desenvolve o potencial da comunidade local com base na justiça social, na eficiência econômica, preservando e conservando o meio ambiente, capacita seus membros para enfrentarem os desafios da economia, fortalecendo as negociações e a gestão participativa.

Notou-se o quanto é importante a comunidade se organizar para gerar renda, cuidando do meio ambiente, da cultura e do social, pois é a partir da comunidade que se pode elaborar projetos que beneficiam a todos.

A única alternativa que existe para o desenvolvimento excludente e extremamente destruidor do meio ambiente é o desenvolvimento sustentável, pois esse visa a questão ambiental, o ser humano e a comunidade, que, está ao alcance de todos, sendo necessário apenas, desenvolver trabalhos na coletividade, pois, uma nova consciência baseada na inclusão e na colaboração tem emergido numa cultura organizacional, tornando possível um novo mundo, e, conseqüentemente, tem-se uma sociedade integrada com o mesmo propósito, onde a participação de todos os atores sociais é extremamente fecunda na busca do mesmo ideal de desenvolvimento e sustentabiliade, sendo a base de tudo as descobertas individuais e o alinhamento delas com a vontade comum. 
É necessário que as pessoas estejam informadas e abertas para "remover" os obstáculos cognitivos, intelectuais e afetivos que se impõem como inércia, nas formas de pensar e agir da sociedade. Informar é o primeiro passo para começar o processo de transformação.

Neste contexto, há necessidade de desenvolver o processo essencial para o ser humano, isto é, a manutenção do equilíbrio ambiental que lhe permita a sobrevivência, sua expansão e desenvolvimento. É preciso, portanto, reconhecer que os recursos sócioambientais são limitados, e contribuir para que a comunidade se conscientize dessa realidade e, dessa forma, garantir o equilíbrio entre o sócio/político e ecológico em cada intervenção social, caminhando para uma sociedade sustentável.

\section{REFERÊNCIAS}

ARANHA, L. de A.; MARTINS, M. H. P. Filosofando: introdução à filosofia. São Paulo: Moderna, 1993.

BRASIL. Constituição da Republica Federativa do Brasil (1988). São Paulo: Revista dos Tribunais, 2001.

CUADROS, J; MENACHO, J. Pauta de producción y consumo sostenibles. In: TEOLOGIA del Mercado. Cuadernos Cristianismo y Justicia. n ${ }^{\circ}$ 84. Barcelona, Fundación Luis Espinal,1998, p.30-45.

FARIA, H.; GARCIA, P. Arte e identidade cultural na construção de um mundo solidário. São Paulo: Instituto Polis, 2003.

FIGUEIREDO, P. A alquimia da matéria. Belo Horizonte: Lopes, 1996.

GOLDSMITH, E. El Tão de la ecologia: uma visión ecológica del mundo. Barcelona: Içaria, 1999.

GOMBRICH, E. H. A história da arte. Rio de Janeiro: Guanabara, 1988.

GRACIOLI, M. M. Os saberes dos sapateiros. 2000. Dissertação (Mestrado em Ciências e Práticas Educativas). Universidade de Franca.

JANSON, H. W; JANSON, A. Iniciação à história da arte. São Paulo: Martins Fontes,1996.

SACHS, I. Desenvolvimento: includente, sustentável, sustentado. Rio de Janeiro: Garamond, 2004. 
